\title{
Avaliação da resposta terapêutica nas alergias oculares por meio da citologia esfoliativa
}

\author{
Evaluation of the therapeutic response in ocular allergies through exfoliativecytology
}

\author{
Haroldo de Lucena Bezerra ${ }^{1}$ \\ Luiz Vicente Rizzo ${ }^{2}$ \\ Maria Cecília Zorat $\mathbf{Y u}^{3}$ \\ Denise de Freitas ${ }^{4}$
}

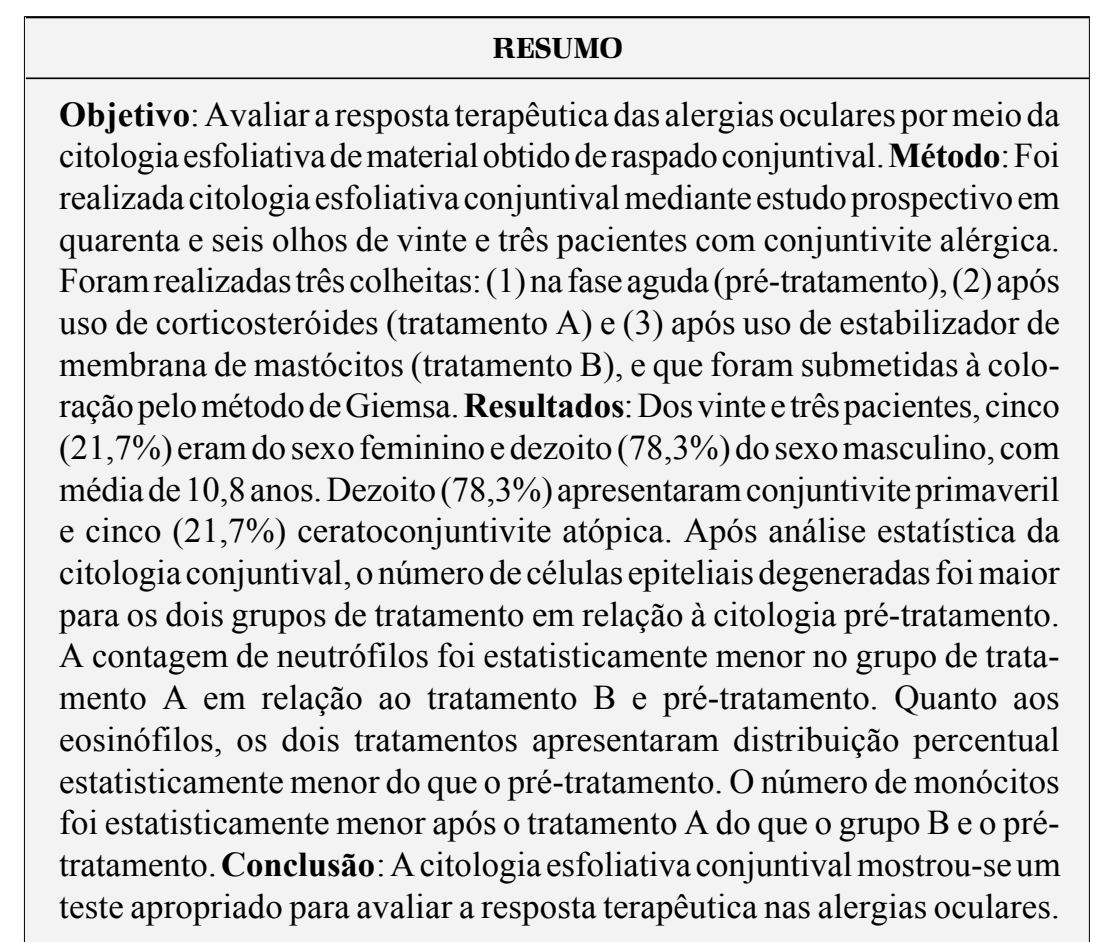

Descritores: Conjuntivite alérgica/quimioterapia; Conjuntivite alérgica/diagnóstico; Contagem de células; Eosinófilos

\section{INTRODUÇÃO}

A citologia tem sido usada nas diversas especialidades médicas como método de diagnóstico principalmente na ginecologia, no diagnóstico de entidades malignas do colo uterino; na hematologia, no diagnóstico de anemias e leucemias, e nas doenças infecciosas, especialmente nas meningites, por meio do estudo do fluido cérebro-espinhal, com grande importância clínica na elucidação diagnóstica e no prognóstico ${ }^{(1)}$.

O diagnóstico da conjuntivite alérgica é clínico, podendo ser confirmado por meio da citologia ${ }^{(2)}$. Na conjuntiva utilizamos a citologia esfoliativa $^{(3)}$. O Giemsa é o corante mais utilizado em citologia esfoliativa para o estudo das doenças externas oculares ${ }^{(3)}$.

Os tipos celulares mais importantes que podem ser evidenciados na citologia ocular conjuntival são as células epiteliais, células caliciformes, células epiteliais multinucleadas, neutrófilos, mononucleares (linfócitos e monócitos), eosinófilos e basófilos/mastócitos ${ }^{(1,4)}$.

Herbert ${ }^{(5)}$, em 1903, foi o primeiro autor a chamar atenção para a eosinofilia conjuntival no diagnóstico de conjuntivite alérgica e, até hoje, o di- 
agnóstico laboratorial de alergia ocular freqüentemente baseia-se na presença de eosinófilos na citologia conjuntival ${ }^{(6-7)}$. Os neutrófilos também são encontrados na citologia da conjuntivite alérgica ${ }^{(8-9)}$; tendo sido citada por Kimura \& Thygeson em $1955^{(10)}$.

O tratamento das alergias oculares deve propiciar o alívio dos sintomas e a prevenção das seqüelas oculares. Dentre as drogas utilizadas podemos citar os estabilizadores de membrana de mastócitos que previnem a degranulação dos mastócitos, inibindo a liberação de mediadores químicos inflamatórios pré-formados como a histamina e fator quimiotáxico eosinofílico, além de inibir a síntese de prostaglandinas e leucotrie$\operatorname{nos}^{(11-12)}$. Já os corticosteróides atuam inibindo a fosfolipase $\mathrm{A}_{2}$, suprimindo a produção de ácido araquidônico e, consequentemente, seus mediadores inflamatórios; atuam também diminuindo a captação de antígenos, a inflamação e a permeabilidade vascular ${ }^{(13-14)}$.

O objetivo do presente trabalho é avaliar a resposta terapêutica através da citologia esfoliativa de material obtido de raspado conjuntival em pacientes com conjuntivite alérgica.

\section{MÉTODO}

Foi realizado um estudo prospectivo de quarenta e seis olhos de vinte e três pacientes com diagnóstico clínico de conjuntivite alérgica primaveril ou atópica no Setor de Doença Externa Ocular e Córnea do Departamento de Oftalmologia da Universidade Federal de São Paulo - UNIFESP/EPM, após aprovação do Comitê de Ética da instituição.

Os pacientes foram submetidos à propedêutica oftalmológica completa e em seguida o exame citológico obtido do raspado conjuntival. Foram realizadas três colheitas de material conjuntival. A primeira colheita foi realizada na consulta inicial, quando os pacientes estavam em fase de agudização do quadro de conjuntivite e sem uso de medicação tópica ou sistêmica. Após a colheita, os pacientes foram medicados com colírio de dexametasona a $0,1 \%$ (Tratamento A). O retorno do paciente deu-se no $16^{\circ}$ dia do início do estudo, sendo então submetidos à segunda colheita. Neste momento, suspendiam o uso da dexametasona tópica e medicados com um estabilizador de membrana de mastócito, a lodoxamida a $0,1 \%$, (Tratamento B). No $31^{\circ}$ dia de estudo, o paciente retornava para avaliação, realizando-se a última colheita. Imediatamente após a realização do esfregaço, as lâminas foram submetidas à coloração pelo método de Giemsa ${ }^{(15)}$.

A análise dos esfregaços foi realizada por dois observadores de laboratórios distintos de maneira mascarada. Na análise estatística dos resultados foram aplicados os testes de Wilcoxon e Spearman ${ }^{(16)}$. Fixou-se em 0,05 ou $5 \%(\alpha<0,05)$ o nível de rejeição da hipótese de nulidade.

\section{RESULTADOS}

Foram examinados vinte e três pacientes, dos quais cinco $(21,7 \%)$ eram do sexo feminino e dezoito $(78,3 \%)$ do sexo masculino. As idades variaram de seis a dezenove anos, com média de 10,8 anos. Dentre os tipos de conjuntivite alérgica observou-se que dezoito $(78,3 \%)$ apresentaram diagnóstico clínico de conjuntivite primaveril e cinco $(21,7 \%)$ de ceratoconjuntivite atópica.

Em relação à citologia conjuntival, a comparação entre os dois tratamentos e a citologia inicial teve em sua análise a média da distribuição percentual de cada variável formada pela média dos dois olhos e das duas lâminas, uma vez que foram colhidas lâminas com e sem albumina.

Para as células epiteliais íntegras, em degeneração e linfócitos, não houve diferença entre os dois tratamentos entre si e tão pouco para a citologia pré-tratamento.

A distribuição percentual do número de células epiteliais degeneradas foi estatisticamente maior para os dois grupos de tratamento em relação à citologia pré-tratamento, embora não foi encontrada diferença entre os dois tratamentos (gráfico 1).

$\mathrm{O}$ número de neutrófilos foi estatisticamente menor no grupo de tratamento A tanto em relação ao tratamento B quanto a citologia pré-tratamento, sendo que os dois últimos não atingiram significância estatística (gráfico 2).

Quanto aos eosinófilos, não foi encontrada diferença entre os dois tratamentos, porém ambos apresentaram distribuição percentual estatisticamente menor em relação à citologia prétratamento (gráfico 3).

Para os monócitos, a distribuição foi estatisticamente menor para o grupo de tratamento $\mathrm{A}$ em relação tanto ao grupo $\mathrm{B}$ quanto a citologia pré-tratamento e estes dois não apresentaram diferença estatisticamente significativa (gráfico 4).

Mastócitos não foram observados em nenhuma das fases dos exames citológicos realizados.

\section{DISCUSSÃO}

Para efeito de estudo citológico, adotamos que as células epiteliais fossem divididas em íntegras, em degeneração e degeneradas, na tentativa de representar a magnitude do processo inflamatório-destrutivo ${ }^{(9)}$.

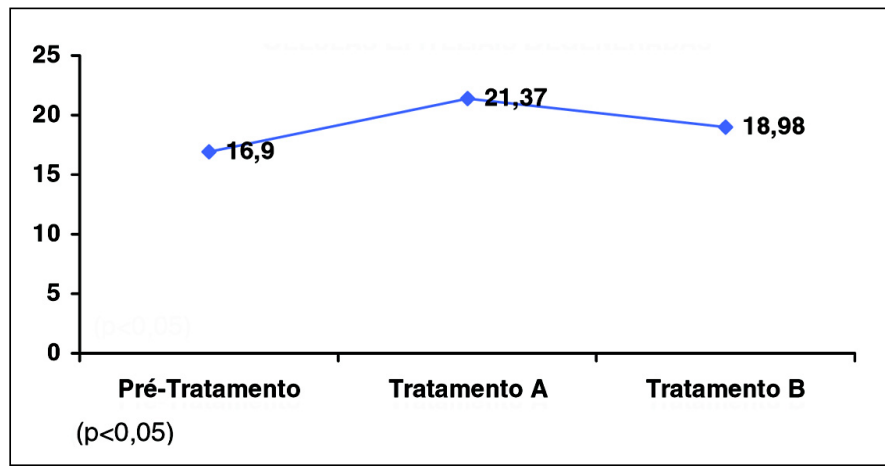

Gráfico 1 - Média do número de células epiteliais degeneradas no prétratamento, após uso de corticosteróides (Tratamento A) e após uso de estabilizador de membrana de mastócitos (Tratamento B) em pacientes com conjuntivite alérgica 


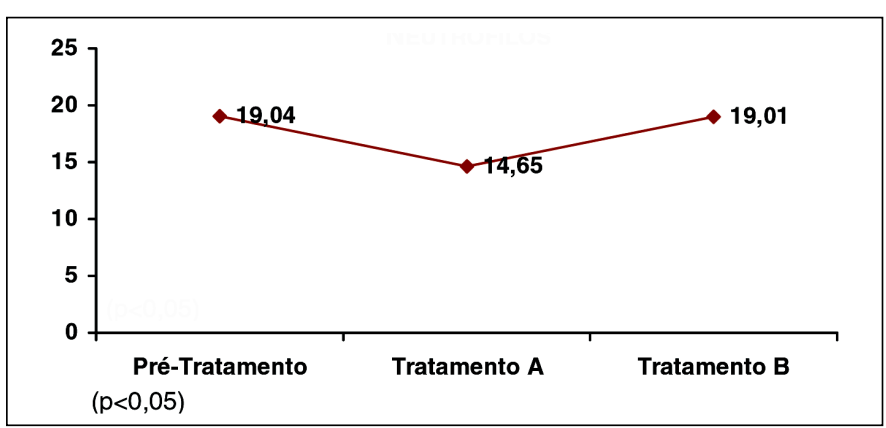

Gráfico 2 - Média do número de neutrófilos no pré-tratamento, após uso de corticosteróides (Tratamento A) e após uso de estabilizador de membrana de mastócitos (Tratamento $B$ ) em pacientes com conjuntivite alérgica

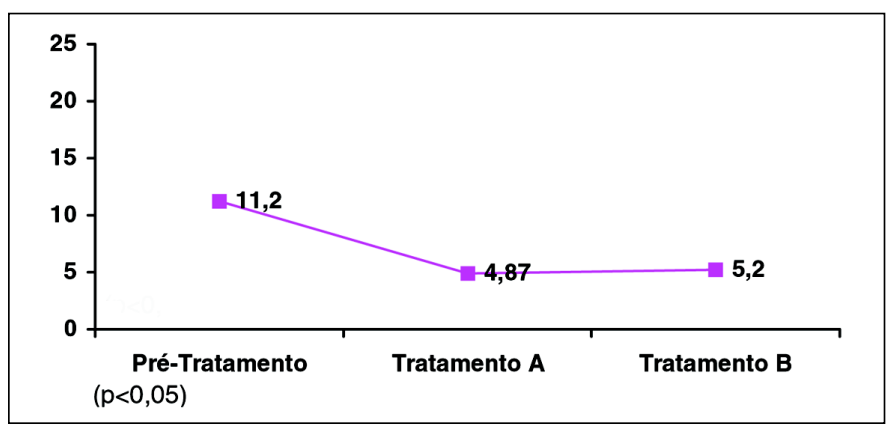

Gráfico 3 - Média do número de eosinófilos no pré-tratamento, após uso de corticosteróides (Tratamento A) e após uso de estabilizador de membrana de mastócitos (Tratamento $\mathrm{B}$ ) em pacientes com conjuntivite alérgica

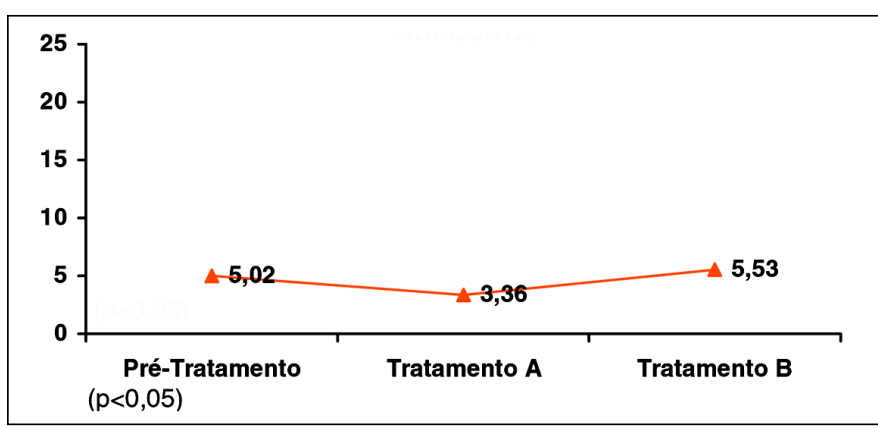

Gráfico 4 - Média do número de monócitos no pré-tratamento, após uso de corticosteróides (Tratamento A) e após uso de estabilizador de membrana de mastócitos (Tratamento B) em pacientes com conjuntivite alérgica

Com relação ao número de células epiteliais degeneradas (gráfico 1), houve um aumento significativo na sua distribuição percentual após a administração de corticosteróides. Durante o processo inflamatório, as células epiteliais da conjuntiva e da córnea tornam-se hipertrofiadas e facilmente desprendem-se, sem apresentar alterações marcantes ${ }^{(17)}$. Atuando sobre células inflamatórias, os corticosteróides promovem redução, principalmente do número de eosinófilos e neutrófilos, não produzindo efeito sobre outros tipos celulares ${ }^{(17)}$. Tendo em vista que a contagem do número de células obedeceu uma distribuição percentual, uma redução no número de eosinófilos e neutrófilos poderia ter acarretado um aumento relativo no número de células epiteliais.
Na fase aguda da conjuntivite alérgica, foi possível identificar neutrófilos no esfregaço, numa proporção de aproximadamente $19 \%$ das células observadas em cada lâmina (gráfico 2). Houve uma diminuição significativa no número de neutrófilos após a administração de corticosteróides. Os corticosteróides agem inibindo a ação da enzima fosfolipase suprimindo a produção de ácido araquidônico e consequentemente de seus mediadores inflamatórios, restabelecendo, por conseguinte, a permeabilidade vascular inicial, diminuindo a mobilização e o influxo de células inflamatórias para os tecidos conjuntivais ${ }^{(13-14)}$. Os neutrófilos são células efetoras em muitas respostas inflamatórias, como nas conjuntivites agudas e crônicas ${ }^{(10,18)}$, principalmente nas conjuntivites causadas por bactérias e fungos $^{(19)}$. Entretanto Kimura \& Thygeson ${ }^{(10)}$, em 1955, afirmaram que uma reação eosinofílica da conjuntiva poderia ser acompanhada com uma reação neutrofílica em pacientes com conjuntivite alérgica na ausência de afecção bacteriana associada.

Após a administração de estabilizador de membrana de mastócitos, o número de neutrófilos pode retornar a seus valores iniciais ${ }^{(20)}$, o que aconteceu no estudo (gráfico 2).

Apesar da lodoxamida exercer um efeito protetor, impedindo a degranulação dos mastócitos e o efeito tóxico induzido pelos eosinófilos no epitélio corneano, há poucas evidências de sua atuação na redução do número de células inflamatórias e de mediadores já liberados pelos mastócitos na conjuntiva de pacientes com conjuntivite alérgica. Apenas um estudo efetuado por Bonini et al. (1997) ${ }^{(20)}$ detectou redução significativa nos níveis de neutrófilos e eosinófilos na lágrima de pacientes tratados com estabilizador de membrana de mastócitos.

O eosinófilo é a principal célula envolvida no diagnóstico da alergia ocular evidenciada através da citologia do raspado conjuntival, sendo considerada a célula característica da inflamação alérgica ${ }^{(18,21)}$. Sua ausência no raspado conjuntival não exclui o diagnóstico de alergia ocular ${ }^{(22-23)}$.

$\mathrm{Na}$ fase aguda da conjuntivite alérgica, o eosinófilo foi encontrado em $78,2 \%$ dos casos consubstanciando assim os dados da literatura, uma vez que a prevalência de eosinófilos na citologia do raspado conjuntival pode variar de 20 a $80 \%{ }^{(22-26)}$.

A degranulação dos mastócitos promove a liberação de mediadores inflamatórios e dentre estes podemos citar o fator quimiotáxico eosinofílico, responsável pela quimiotaxia dos eosinófilos para os tecidos conjuntivais ${ }^{(27-28)}$. O próprio prurido ocular, através de um mecanismo irritativo pode recrutar células inflamatórias para a conjuntiva ${ }^{(29)}$.

Com a instituição do corticosteróide houve uma redução significativa do número de eosinófilos conjuntivais (gráfico 3). Após o uso de estabilizador de membrana de mastócitos, a citologia mostrou uma manutenção do número de eosinófilos conjuntivais. O estabilizador de membrana de mastócitos regula a sua degranulação, impedindo a liberação de mediadores inflamatórios, principalmente o fator quimiotáxico eosinofílico e inibe os efeitos tóxicos dos produtos derivados dos eosinófilos no epitélio corneano ${ }^{(28)}$. Ainda foi possível evidenciar essas células nas lâminas do raspado conjuntival após a te- 
rapêutica administrada, concluindo-se que tanto na fase ativa da doença quanto no período entre as crises é possível encontrarmos eosinófilos na conjuntiva ${ }^{(18)}$.

Os monócitos também estiveram presentes na citologia dos nossos pacientes com alergia ocular. Houve uma redução significativa no número de monócitos após a administração de corticosteróides, retornando aos níveis anteriores após o uso de estabilizadores de membrana de mastócitos (gráfico 4). Geralmente presente nas conjuntivites virais, a presença de monócitos na conjuntivite alérgica já havia sido mencionada na literatura ${ }^{(30)}$.

Não se evidenciou a presença de mastócitos nos esfregaços. Estes têm sido identificados através da biópsia, na região subepitelial da conjuntiva, com uma maior concentração na substância própria do tecido conjuntival de pacientes alérgi$\cos ^{(28,31)}$. Sua ausência não exclui o diagnóstico nem compromete a participação dos mastócitos na alergia ocular ${ }^{(31)}$.

\section{CONCLUSÃO}

Após o uso de corticosteróides e estabilizadores de membrana de mastócitos, a citologia esfoliativa conjuntival mostrou-se um teste apropriado para avaliar a resposta terapêutica em pacientes com conjuntivite alérgica.

\section{ABSTRACT}

Purpose: To evaluate the therapeutic response of ocular allergies through exfoliative cytology of conjunctival scrappings. Method: Conjunctival exfoliative cytology was performed through a prospective study in forty six eyes of twenty-three patients with clinical diagnosis of allergic conjunctivitis. Three scrappings were performed: (1) in the pre-treatment period, (2) after use of corticosteroids (treatment A) and (3) after use of mast cell stabilizer (treatment B); in two types of smears, with and without albumin. The smears were stained with Giemsa. Results: Of the twenty-three patients, five $(21.7 \%)$ were female and eighteen $(78.3 \%)$ male, with an average of 10.8 years. Eighteen $(78.3 \%)$ presented vernal conjunctivitis and five $(21.7 \%)$ atopic keratoconjunctivitis. After statistical analysis of the conjunctival cytology, the number of degenerate epithelial cells was higher in the two treatment groups in relation to the pre-treatment period. The number of neutrophils was smaller in the A treatment group than in the B treatment and pre-treatment groups. Regarding the number of eosinophils, the two treatments presented a lower percentile distribution than that of the pre-treatment period. The number of monocytes was smaller after the A treatment than the B group and the pre-treatment period. Conclusion: Exfoliative conjunctival cytology is an appropriate test to evaluate the therapeutic response in ocular allergies.

Keywords: Conjunctivitis, allergic/drug therapy; Conjunctivitis, allergic/diagnosis; Cells count; Eosinophils; Cytological techniques

\section{REFERÊNCIAS}

1. Byrne KA, Tabbara KF, Burd EM, Hyndiuk RA. Diagnostic microbiology and cytology of the eye. Newton: Butterworth-Heinemann; 1995.

2. Friedlaender $\mathrm{MH}$. Conjunctivitis of allergic origin: clinical presentation and differential diagnosis. Surv Ophthalmol 1993;38(suppl.):105-14.

3. Stenson S. Cytologic Diagnosis. A. The Anterior Segment Cytopathology. In: Karcioglu ZA. Laboratory Diagnosis in Ophthalmology. New York: Macmillan Publishing Company; 1987. p.90-107.

4. Tomimatsu P. Citologia conjuntival e corneana. In: Belfort Jr R, Almada AT, Tomimatsu P. Doenças externas oculares. São Paulo: Roca; 1981. p.3-14.

5. Herbert H. Preliminary note on the pathology and diagnosis of spring catarrh. Brit M J 1903;2:735.

6. Friedlaender MH. Ocular allergy. Int Ophthalmol Clin 1985;25:35-41.

7. Friedlaender MH. Ocular allergy. J Allergy Clin Immunol 1985;76:645-57.

8. Naib ZM, Clepper AS, Elliott SR. Exfoliative cytology as a aid in the diagnosis of ophthalmic lesions. Acta Cytol 1967;11:295-303.

9. Bonini S, Bonini S, Vecchione A, Naim DM, Allansmith MR, Balsano F. Inflammatory changes in conjunctival scrapings after allergen provocation in humans. J Allergy Clin Immunol 1988;82:462-9.

10. Kimura SJ \& Thygeson P. The cytology of external ocular disease. Am J Ophthalmol 1955;39:137-45.

11. Allansmith MR \& Ross RN. Ocular allergy and mast cell stabilizers. Surv Ophthalmol 1986;30:229-44.

12. Oliveira AHV, Dantas MCN, Holzchuh N, Dantas PEC. Comparação entre a eficácia do $\mathrm{N}$ acetil aspartil glutamato de sódio (NA-AGA) e do cromoglicato dissódico a $4 \%$ no tratamento da conjuntivite primaveril. Arq Bras Oftalmol 1996;59:470-5.

13. Portelinha WM, Belfort Jr R, Molinari H. Cromoglicato dissódico e corticóide tópico nas conjuntivites atópicas crônicas e primaveris. Arq Bras Oftalmol 1978;41:105-8.

14. Friedlaender MH. Corticosteroid therapy of ocular inflammation. Int Ophthalmol Clin 1983;23:175-82.

15. Melvin DM \& Brooke MM. Triton X-100 in Giemsa staining of blood parasites. Stain Technol 1955;30:269-75.

16. Siegel S \& Castellan Jr. NJ. Nonparametric Statistics. New York: Mac GrawHill Int. Ed. 2a ed. 1988; p.399.

17. Naib ZM. Cytology of ocular lesions. Acta Cytol 1972;16:178-85.

18. Thygeson P. The cytology of conjunctival exudates. Am J Ophthalmol 1946; 29:1499-1512.

19. Palestine AG, Meyers SM, Fauci AS, Gallin JI. Ocular findings in patients with neutrophil dysfunction. Am J Ophthalmol 1983;95:598-604.

20. Bonini S, Schiavone M, Bonini S, Magrini L, Lischetti P, Lambiase A, Bucci MG. Efficacy of Lodoxamide Eye Drops on Mast Cells and Eosinophils after Allergen Challenge in Allergic Conjunctivitis. Ophthalmology 1997; 104:849-53.

21. Freitas D \& Belfort Jr R. Conjuntivites. Arq Bras Oftalmol 1992;55:196-205.

22. Friedlaender MH, Okumoto M, Kelley J. Diagnosis of Allergic Conjunctivitis. Arch Ophthalmol 1984;102:1198-9.

23. Abelson MB, Madiwale N, Weston JH. Conjunctival Eosinophils in Allergic Ocular Disease. Arch Ophthalmol 1983;101:555-6.

24. Higuchi M \& Ohno S. A clinical study on allergic conjunctivitis. Acta Soc Ophthalmol Jap 1981;85:1778-83.

25. Stenson S, Newman R, Fedukowicz H. Laboratory Studies in Acute Conjunctivitis. Arch Ophthalmol 1982;100:1275-7.

26. Kari O. Atopic conjunctivitis: A cytologic examination. Acta Ophthalmol 1988; 66:381-6.

27. Wasserman SI, Goetzl EJ, Austen KF. Preformed eosinophil chemotactic factor of anaphylaxis (ECF-A). J Immunol 1974;112:351-8.

28. Butrus SI \& Abelson MB. Laboratory evaluation of ocular allergy. Int Ophthalmol Clin 1988;28:324-8.

29. Greiner JV, Peace DG, Baird RS, Allansmith MR. Effects of eye rubbing on the conjunctiva as a model of ocular inflammation. Am J Ophthalmol 1985; 100:45-50.

30. Braude LS \& Chandler JW. Atopic corneal disease. Int Ophthalmol Clin 1984;24:145-56.

31. Morgan SJ, Williams JH, Walls AF, Church MK, Holgate ST, McGill JI. Mast cell numbers and staining characteristics in the normal and allergic human conjunctiva. J Allergy Clin Immunol 1991;87:111-6. 